\title{
Coping with Loneliness in Old Age: A Cross-Cultural Comparison
}

\author{
AMI ROKACH AND TRICIA ORZECK. \\ Institute for Study \& Treatment of Psychosocial Stre:s, Toronto
}

\author{
FELIX NETO \\ Universidade do Porto, Portugal
}

\begin{abstract}
The present study is an examination of the influence of cultural background on the ways in which the aged cope with loneliness. Thirty-six participants from Canada and 105 from Portugal (60-83 years old) answered an 86-item questionnaire which examined the beneficial strategies which they used to cope with loneliness. The strategies which were examined included Acceptance and Reflection, Self-Development and Understanding, Social Support Network, Distancing and Denial, Religion and Faith, and Increased Activity. Results indicated that the elderly of the two cultures differ on three subscales. Gender differences between and within cultures were also examined.
\end{abstract}

\section{INTRODUCTION}

$\mathrm{C}$ urrent research points out the pervasiveness of loneliness and its debilitating effects (Jones, Rose, \& Russell, 1990: Rokach \& Brock, 1998). As Sadler (1987) observed "many of us in today's world are living on the verge of a lonely life. A significant number of us have experienced the ravages of loneliness; some of us have become debilitated, depressed and demoralized by it" (p. 184). Loneliness has been linked to such maladies as depression, suicide, hostility, alcoholism, poor self-concept, and psychosomatic illnesses (McWhirter, 1990) and although most research was conducted in North America, it is clear that the negative implications of loneliness are felt regardless of the culture in which it occurs.

Largely, loneliness research tended to focus on individual factors, i.e. either on personality factors or lack of social contacts (Jylha \& Jokela, 1990). However, if we accept the premise that loneliness is expressive of the individual's relationship to the community, then it is conceivable that the difference amongst cultures and the ways people's social relations are organized within them will result in cross-cultural variations in the way people perceive, experience and cope with loneliness. Wilson, Sibanda, Sibanda, and Wilson (1989) asserted that little cross-cultural research on loneliness exits. Ginter, Glauser, and Richmond (1994) further pointed out the importance and urgency for cross-cultural research.

The elderly frequently suffer from a variety of chronic ailments (Roy, 1986), death of friends or a spouse (Rabasca, 1999), and social isolation to varying degrees (Delisle, pp. 124-137. 
1988). Old age often brings a "realignment" of public and private selves (Larson, 1990). Retirement and old age also bring a diminution in a person's role, within and outside of the family (Rosow, 1976). However, Larson (1990) and VanderVoort (1999) asserted that it is the quality rather then the quantity of one's social involvement which is more important. And so, although the elderly may spend less time interacting with others, their relationships may be more fulfilling and nurturing.

Those changing circumstances, life events and opportunities which the elderly face, undoubtedly affect the manner in which people experience, evaluate, and cope with life's demands. Ernst and Cacioppo (1999) asserted that there is an overall positive correlation between loneliness and age. However, when age-related factors are taken into account, it appears that the relationship between loneliness and age is more complex. Loneliness is reported to be experienced most intensely during adolescence, and then it declines as age increases despite the loss commonly experienced in old age (Peplau, Bikson, Rook, \& Goodchilds: 1982; Revenson \& Johnson, 1984). The present study is, in essence, a phenomenological study. Unlike other research (see Ernst \& Cacioppo, 1999) it is not diagnostic in nature, but rather, it aims at understanding, explaining, and highlighting the various strategies that the elderly use to cope with loneliness.

Segall, Lonner, and Berry (1998) reviewed the interplay between psychology and culture, and asserted that "culture and all that it implies with respect to human development, thought and behaviour should be central, not peripheral in psychological theory and research" (p. 1108). Medora, Woodward, and Larson (1987) maintained that "among the important factors affecting the individual's experience of loneliness are the culture and the family in which he/she develops" (p. 205). Consequently, the difference of social tapestry, interpersonal interactions, and the support networks which are available to individuals in various cultures and countries are, naturally, bound to effect the manner in which they cope with loneliness. The present study focused on the aged in two diverse populations: the North American one (as exemplified in this case by the Canadian participants) and the Portuguese. These two cultures differ geographically, religiously, economically, and socially.

\section{The North American Culture}

It has been frequently pointed out (Schneider, 1998; Sermat, 1980) that loneliness is prevalent and may even be encouraged by the North American culture. Ostrov and Offer (1980) had reasoned that the North American culture emphasizes individual achievement, competitiveness, and impersonal social relations. Consequently, loneliness may be quite pronounced in the face of such socially alienating values. Saxton (1986) argued that in contemporary North American society, there is a decline in primary group contacts. Those are the face-to-face, intimate contacts with family members, relatives, and close friends which were much more prevalent several decades ago. As has been the case since the 1960s, residential mobility is enhancing loneliness in North America by causing people to remain uninvolved in their social groups due to their acute awareness of an impending move (Packard, 1972; Walker, 
1966). In addition, large metropolitan areas, with their large apartment complexes, social prejudice, and fear of crime, add to people's reluctance to interact and get involved with each other (Medora, Woodward, \& Larson, 1987). Schneider (1998) reported that the North American culture is inadequate of symptom reduction and adjustment as criteria for psychological well-being (Breggin, 1991). He pointed out that normality in America is associated with such conditions as spiritual and emotional emptiness (Cushman, 1995), Type A personality, and workaholism (Fassel, 1990) factors that have been demonstrated to erode physical and mental health (Bracke \& Bugental, 1995). Coupled with the increased computerization and Internet use, this culture magnifies the individual's social alienation, limited contact with others (within and without one's family), and loneliness (Kraut, Patterson. Lundmark, Kiesler, Mukopadhyay, \& Scherlis, 1998). Since the American and the Canadian cultures share a common language, geographical proximity, a flow of visitors between the countries, commercial interconnections, and economical alliances, the Canadian sample will be examined as part of the North American culture.

\section{The Portuguese Culture}

Portugal is a small country sharing its eastern border with Spain in Western Europe. The population in Portugal is among the most homogenous in Europe. Portuguese is the sole language and nearly the entire population is Roman Catholic (Encyclopedia of world geography, 1994). For centuries, the most distinctive feature of Portugal's social structure was its remarkable stability. The system consisted of a small elite at the top, a huge mess of peasants at the bottom, and almost no one in between (Solsten, 1994). Moreover, the extended family and kinship relations are of great importance. For instance, unlike the North American custom, the role of the godparent implies certain lifetime obligations, such as helping a godchild in trouble, arranging admission to school, or finding employment, while the godchild exhibits loyalty and devotion to the godparent. The system is one of patronage based on mutual obligation. Outside of the nuclear family the kin relations are weaker (Solsten, 1994). For the past two decades, relations within the family came to resemble those of the rest of Western Europe, i.e. the family became a more democratic entity (Encyclopedia of world geography, 1994). Marriage and kinship networks are often based on social and political factors in addition to love and interpersonal attraction. It has been said that to a degree that often surprises outsiders, many Portuguese marriages are arranged, even in the 1990s (Solsten, 1994).

Loneliness research tends to focus on individual factors, that is, either on personality factors or lack of social contacts (Jylha \& Jokela, 1990). However, loneliness could be expressive of the individual's relationship to the community. It is conceivable, then, that the difference amongst cultures and the ways people's social relations are organized within them will result in variations in the way people experience loneliness. The present study aimed at examining the difference in the experience of loneliness for the aged who were born and raised in different cultures. 


\section{METHOD}

\section{Participants}

One hundred and forty one participants were invited, on a volunteer basis to answer the loneliness questionnaire. The average age of the 141 participants was 66.2 years (range: 60-83) and the mean education was 9.65 years (range: 2-18). Fifteen percent of the participants were single, $38 \%$ married, and $47 \%$ widowed, separated, or divorced. Table 1 outlines the breakdown of genders, age, and educational level within each culture.

\section{The Loneliness Questionnaire}

All items for the questionnaire were written by the senior author and based on Rokach's previous research on loneliness (Rokach, 1990). That study yielded a theoretical model of coping with loneliness as reported by five hundred and twenty-six (526) participants who were asked to describe the strategies which they employed in coping with loneliness and which proved to be beneficial to them. The present items were chosen from those descriptions and were modified to provide clarity and gender neutrality. The first draft was reviewed by six psychologists and two psychology students for any items or instructions which might be lacking in clarity, relevance, or content. The questionnaire was then constructed incorporating this feedback. The questionnaire has 86 items that describe a variety of beneficial coping strategies. The general instructions requested that participants reflect on their previous experiences of loneliness and endorse the items that described the coping strategies that were most helpful to them. They were assured of anonymity and were not asked to identify themselves.

Principal components factor analysis with varimax rotation was applied to the data with .40 being designated as the minimum loading for an item. The factor analytic procedure, using an SPSS program, extracted the principal components, and the factor matrix was then subjected to varimax rotation. The items contributing to the factors could be assigned meaning, and each accounted for a sufficient amount of the variance (at least 3\%) to support statistical meaningfulness. The remaining factors accounted for one or two percent of the variance and so were ignored. Accordingly, repetitions of the varimax rotations were limited to five factors each to permit the results to be restricted to the most robust factors.

All 86 items in the questionnaire were taken from Rokach and Brock (1998). The strategies were grouped into six factors: Factor 1, Reflection and Acceptance $(14 \%)=$ being by one's self to become acquainted with one's fears, wishes, and needs; and consequently, accepting one's loneliness and its resultant pain; Factor 2, Self-Development and Understanding $(5 \%)=$ the increased self-intimacy, renewal, and growth which are often the results of active participation in organized focused groups or of receiving professional help and support; Factor 3, Social Support Network $(4 \%)=$ the re-establishing of social support network which can help one feel connected to and 
valued by others; Factor 4, Distancing and Denial $(3 \%)=$ denial of the experience and pain of loneliness by alcoholism, drug abuse, and other deviant behaviors; Factor 5, Religion and Faith $(3 \%)=$ the need to connect to and worship a divine entity. Through affiliation with a religious group and practicing its faith one can gain strength, inner peace, and a sense of community and belonging; and Factor 6, Increased activity (3\%) $=$ active pursuit of daily responsibilities as well as fun-filled solitary or group activities, thus maximizing one's social contacts (See appendix A for sample items). Each of the six factors comprised a subscale and participants' scores are the sum of items they endorsed in each subscale. Kuder-Richardson internal consistency reliabilities were calculated and yielded the following alpha values: $F_{1}=.89 ; F_{2}=.74 ; F_{3}=.60 ; F_{4}=$ $.55 ; \mathrm{F}_{5}=.70 ; \mathrm{F}_{6}=.55$. K-R alpha for the 86-item questionnaire was .94 .

\section{Procedure}

Participants took an average of approximately fifteen minutes to complete the questionnaire. The general instructions required that the participants endorse the items which describe their loneliness experiences. They were assured of anonymity. Participants were recruited, on a volunteer basis, in community centers, centers for the aged, malls, and physicians' waiting rooms.

\section{RESULTS}

Table 1 outlines the breakdown of gender, marital status, educational level, and age. A gender by culture Chi square analysis $\left(\mathrm{X}_{(1,1)}^{2}=20.25 ; \mathrm{p}<.001\right)$ yielded significant differences amongst the two cultures. No significant marital status differences were found $\left(\mathrm{X}_{(1,2)}^{2}=3.08\right.$, n.s. $)$. Age by culture one way ANOVA $\left(\mathrm{F}_{(1,139)}=1.80\right.$; n.s. $)$ found age not to be significantly different amongst the two cultures. Additionally, while the Portuguese sample completed on the average 8.98 grades, Canadians completed 11.29 grades. Consequently, a one way ANOVA $\left(\mathrm{F}_{(1,115)}=8.87 ; \mathrm{p}<.001\right)$ showed this to be a significant difference.

Table 2 compared the mean subscale scores on each of the five factors amongst the two cultural groups using a Mancova (age and gender were covaried). The Mancova $\left(F_{(6,108)}=3.65 ; \mathrm{p}<.001\right)$ was significant and consequently univariate Ancovas (age and gender were covaried) for each of the subscales across cultures were conducted.

Results of the present study indicated that the Canadian elderly scored significantly higher than their Portuguese counterparts on Reflection and Acceptance, Distancing and Denial, and Religion and Faith. The mean subscale scores of men and women in the two cultures were not significantly different as were not the mean scores of males across cultures. The mean scores of women across cultures was significantly different $\left(\mathrm{F}_{(6,76)}=2.30 ; \mathrm{p}<.05\right)$. 


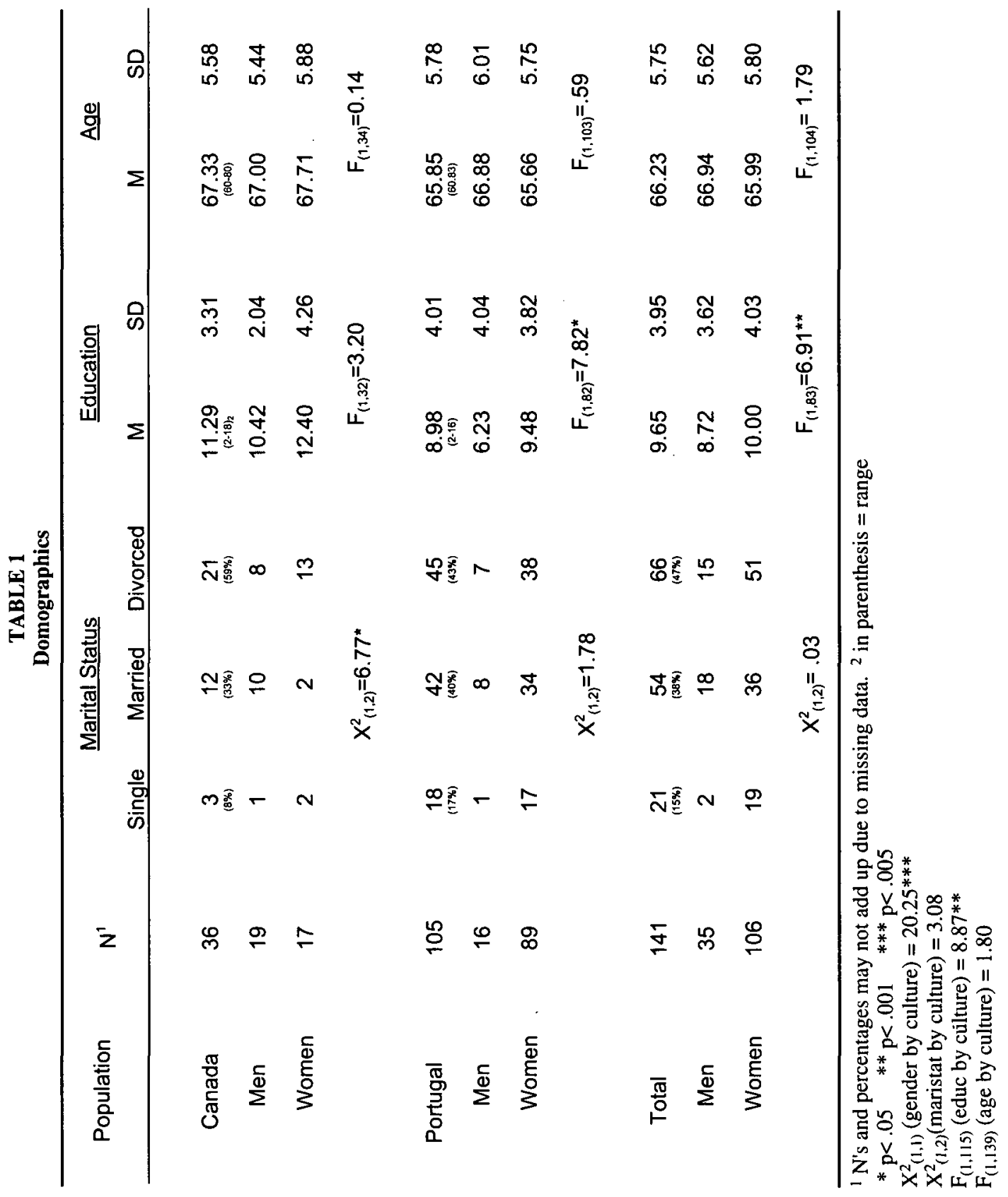




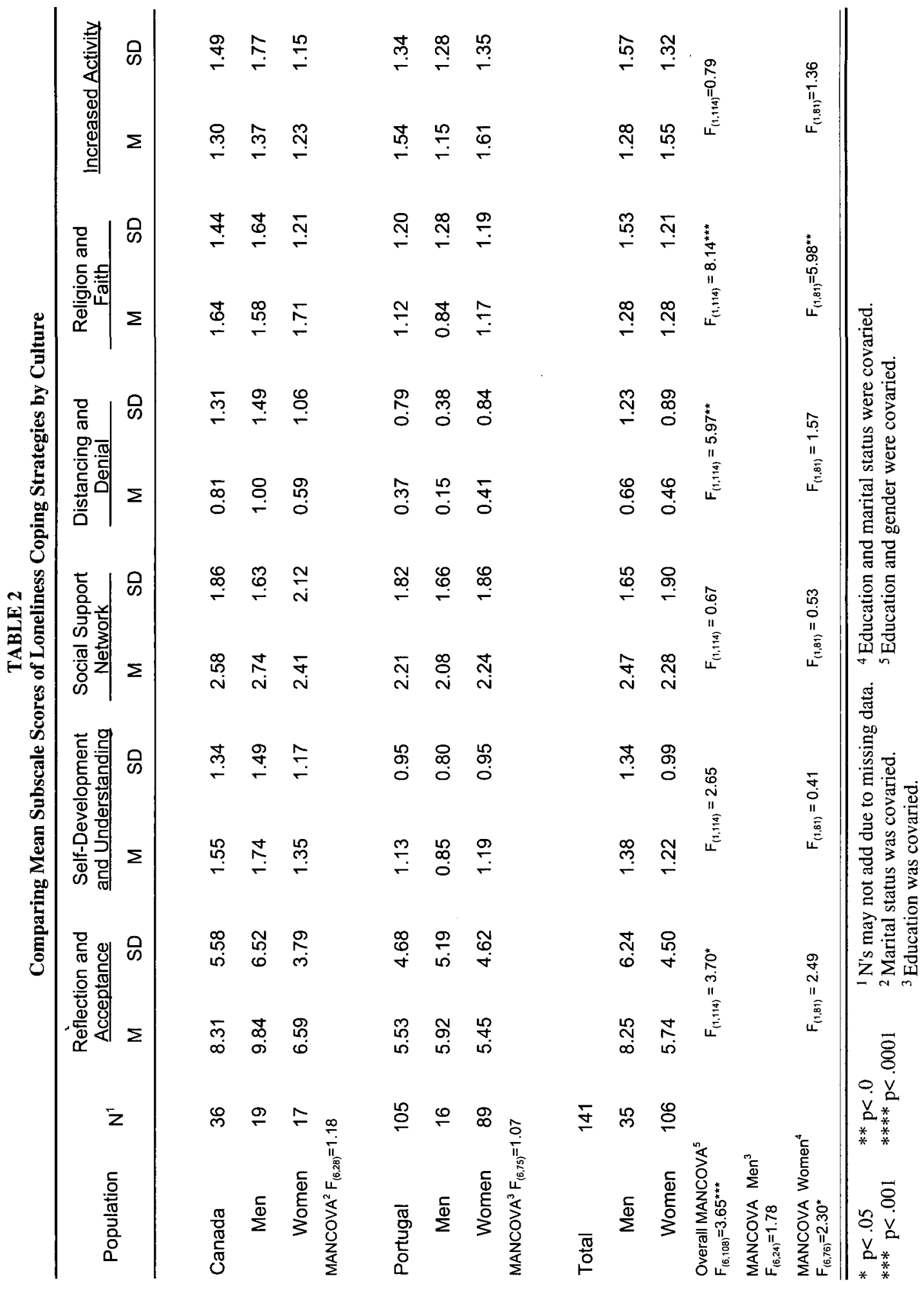




\section{DISCUSSION}

Considerable diversity appears to exist among the coping strategies which are available to the lonely (Rokach \& Brock, 1998), and individual choices of coping strategies are affected by the individual's age, life experience, cultural background, and the availability of methods of alleviating loneliness. To echo the Basic Behavioural Science Task Force (1996) "Social, cultural, and environmental forces shape who we are and how well we function in the everyday world. The culture we belong to, the neighbourhood we live in, and the demographic composition of our community" (p. 722) all profoundly influence mental health, adjustment to daily demands and our ability to cope with loneliness.

Folkman and Moskowitz (2000) pointed out that coping with any stressful stimuli is influenced by individual and social resources (see also McCrae \& John, 1992). Lazarus (2000) underlined those findings and suggested that when examining the coping strategies of large samples, using questionnaires can assist in understanding the "relational meaning that an individual person constructs from the person- environment relationship" (p. 670). Rabasca (2000) pointed out that recent research found that the elderly are more adept at coping with loss and loneliness than previously assumed.

Ornish (1998) stated at the very beginning of his book Love \& Survival: "Our survival depends on the healing power of love, intimacy, and relationships. Physically. Emotionally. Spiritually. As individuals. As communities. As a country. As a culture. Perhaps even as a species" (p. 1). Weil (1997) asserted that the human species are highly social, communal animals that are meant to live in families, tribes, and communities, and when we lack those connections we suffer. However, our western industrialized society glorifies individualism and independence and fosters a spirit of "everyman-to-himself."

The present study examined the technique which the elderly in North America and Portugal employ in coping with loneliness. The present results indicated that cultural background does affect the manner in which the elderly cope with loneliness, particularly their use of Reflection and Acceptance, Distancing and Denial, and Religion and Faith. Interestingly, no gender differences were found in either culture, nor did culture influence the techniques which men employed to cope with loneliness. A significant difference was found where the mean subscale scores of Canadian and Portuguese women were compared.

The Reflection and Acceptance subscale includes items which address the facing and accepting of loneliness, and the consequent enhancement of self-intimacy and inner search. This approach, which is so fundamental to coping with loneliness (Rokach \& Brock, 1998), is most prescribed to by the aged in North America. It emphasizes self-growth, understanding, and acceptance, and the "golden years" offer the time and maturity for reflection on and acceptance of one's journey through life (Brown, 1996).

The significantly lower subscale score of the Portuguese may indicate that either their culture promotes less reflection and self-search, that the elderly-who are very rooted in and surrounded by their families have less time to engage in such solitary 
activities, or that they do indeed engage in reflection, but do not consider it a coping strategy with loneliness.

Andre (1991) referred to this coping strategy as "positive solitude" which he described as the antidote to the sometimes desperate attempts of some people to "find someone." Contemporary belief holds that being alone is related to unhappiness, depression and failure; consequently, the ability to think positively about being aloneand to be content living alone-is not well developed in North America. "A particularly pernicious belief is that the ultimate way to cure loneliness is to find relationships. Alone, it is assumed, people cannot really conquer their loneliness; perhaps they can adjust to it, but they will never be truly happy" (Andre, 1991: p. xix). The author believes that "only when we learn to live alone, and even to love alone-when we face our alienation, our vulnerability, our creativity, our uniqueness, our humanity, and our desires-will the problems of finding others and finding community become less urgent" (p. xix).

The results of the present study suggested that solitude, i.e. welcomed aloneness as opposed to loneliness, seems to aid especially North Americans in coping effectively with the pain of loneliness. Solitude stops attempts to deny loneliness, thereby promoting its acceptance as an existential and, at times, unavoidable human condition. Consequently, solitude facilitates a re-directing of one's inner resources towards greater understanding of one's self, learning to enjoy one's own company, and the planning of ways to overcome the conditions which precipitated the experience of loneliness. Solitude is believed to promote individuality, creativity, and self-awareness by allowing the opportunity for contemplation, self-exploration, and insight.

Considerable diversity appears to exist among the coping strategies of the lonely (Rook, 1988), and as such people differ in their readiness to recognize or admit (to themselves and to others) that they are in pain due to feeling lonely (Booth, 1983; Rook \& Peplau, 1982). Feared stigma and loneliness anxiety-defending against the fear of experiencing loneliness (see Moustakes, 1972) —may result in attempts to deny the experience either outright or by distancing oneself from the pain, feelings of failure, and restlessness and desperation which loneliness entails (Rook, 1988). Distancing and Denial, addresses this issue and confirms the connection found between loneliness and alcoholism, drug abuse, and other behavioral disorders or deviant behaviors (Rook, 1984). Although previous writers (Moustakes, 1961, 1972; Rokach, 1990) emphasized the need to face and accept loneliness as the initial step of coping with its pain successfully, it is interesting that subjects of the present study found that such denial was indeed beneficial.

Self-generated social detachment, or the purposeful avoidance of interacting with others, was identified as an important facet of this factor. It has been suggested (Sullivan, 1953; Weiss, 1973) that loneliness is actually a driving force that motivates people to initiate social interactions, and intuitively one may agree that this could be beneficial in attempting to end loneliness. However, participants in the present study found that the acute pain, suffering, upheaval, and agony suffered while experiencing loneliness were so disturbing and unsettling that they felt they could not comfortably associate 
with others. On the contrary, they reported that the pain and vulnerability caused them to maintain some "space" or detachment from people, both as a measure of protecting their vulnerable self, and as an attempt to minimize further hurt that may be caused to them by failed attempts to associate with others.

An effect which the North American mechanized and atomistic society may have on its people is the need to appear connected, appealing, and romantically sought after, lest the person feels rejected and be seen as a failure (Gordon, 1976; Mijuskovic, 1992; Weintrob, 1987). As Rokach (1999) found, those who grow up in the relatively alienating North American culture with its emphasis on competitiveness and impersonal social relations appear to endorse Distancing and Denial significantly more than those who were not brought up there. Results of the present study are consistent with that previous finding. North Americans scored significantly higher on Distancing and Denial than their Portuguese counterparts, who may not feel the pressure and the need to appear as socially appealing and connected as North Americans do.

Rokach (1988) noted that "In our limitless and awesome universe, which humans have not fully grasped, under harsh social conditions and high personal 'expectation,' a feeling of self-alienation, emptiness and a sense of meaninglessness are almost inevitable" (p. 243). Factor 5, Religion and Faith, appears to confirm such assertion as it suggests that individuals need to feel connected to and/or worship a divine entity, God, or supreme being. Through affiliating with religious groups and practicing their faith, individuals gain strength, inner peace and a sense of community and belonging.

Andre (1991) suggested that one may successfully deal with loneliness by finding solace, and have the "emotional experience of a soothing presence. In a turbulent world solace calms us. In the face of adversity it gives us composure" (p. 108). Andre observed that ritual is an important source of solace, in that it provides rewarding connection to the past and the future, and anchors the individual to time and space. Thus, Religion and Faith may not only provide the person with connectedness to other worshippers but with the solace that comes from feeling related to a protective and powerful supreme being.

Although it has been reported that North Americans do indeed use prayer and the sense of belonging which attendance at religious services entails (Andre, 1991; Rokach \& Brock, 1998) as a way of alleviating the gnawing pain of loneliness, it has not been reported as a widely held strategy that secular people use to cope with loneliness. It is therefore surprising and contrary to expectations that North Americans, rather than the Portuguese who grow up in a mostly Roman Catholic culture would use and benefit from prayer. These results contradict those of a previous study (Rokach, 1999) which suggested that the North American adults score lower on Religion and Faith than those who were raised in more traditional and religious countries. It is, of course, possible that while the Portuguese elderly do indeed pray regularly, they do not consider it as a coping strategy but simply as a familiar way of life.

Examining the genders within each culture suggested no significant difference in the scores of men and women. Contrary to previous studies that examined the gender effects on coping with loneliness (Rokach \& Brock, 1998; Rokach, Ramberan, \& 
Bacanli, 2000), the present results suggested that both elderly men and women in each culture cope similarly with loneliness. The same holds for men across cultures. However, women do appear to cope differently with loneliness, which may point out to cultural differences. Canadian and Portuguese women do not differ on any of the coping strategies but on Religion and Faith. It is not suggested that the Canadian elderly women resort to prayer more than their Portuguese counterpart, but rather that they perceive their religiosity, prayers, and participation in organized religious activities as helpful in coping successfully with loneliness.

To conclude, it appears that cultural background affects the strategies used in coping with loneliness. North American seniors scored the highest on Reflection and Acceptance, Distancing and Denial, and Religion and Faith.

Further research is needed to replicate the present study with a larger participant pool comparing the way of coping with loneliness of elderly from Canada and Portugal to that of people from other cultures. In light of the growing awareness that research conducted in Western cultures does not necessarily represent the psychology of non western populations (Triandis, 1996) the two populations which were compared in this study could also be compared to those of a third world country.

\section{NOTES}

Accepted for publication: January 19, 2004.

Address for correspondence: Ami Rokach, Institute for the Study and Treatment of Psychosocial Stress, 104 Combe Avenue, Toronto, Ontario, Canada M3H 4J9. E-mail: arokach@yorku.ca.

\section{REFERENCES}

Andre, R. (1991). Positive solitude: A practical program for mastering loneliness and achieving self. fulfillment. New York: HarperCollins.

Basic Behavioral Science Task Force of the National Advisory Mental Health Council. (1996). Basic behavioural science research for mental health: Social cultural and environmental processes. American Psychologist, 51 (7), 722-731.

Booth, R. (1983). Toward an understanding of loneliness. Social Work, 23, 116-119.

Bracke, P.E. \& Bugental, J.F.T. (1995). Existential addiction: A model for treating type A behavior and workaholism. In T. Pauchant (Ed.), In search of meaning: Managing for the health of our organizations, our communities, and the natural world (Pp. 65-93). San Francisco: Jossey- Bass.

Breggin, P. (1991). Toxic psychiatry. New York: St. Martin's Press.

Brown, A.S. (1996). The social processes of aging and old age. Upper Saddle River, NJ: Prentice Hall.

Cushman, P. (1995). Constructing the self, constructing America. Reading, MA: Addison-Wesley.

Delisle, M.A. (1988). What does solitude mean to the aged? Canadian Journal of Aging, 7, 358-371.

Encyclopedia of world geography (1994). Spain and Portugal, (Vol. 10). New York: Marshall Cavendish.

Ernest, J.M., \& Cacciopo, J.T. (1999). Lonely hearts: Psychological perspectives on loneliness. Applied and Preventive Psychology, 8, 1-22.

Fassel, D. (1990). Working ourselves to death. San Francisco: Harper.

Folkman, S., \& Moskowitz, J.T. (2000). Positive affect and the other side of coping. American Psychologist, S5 (6), 647-654.

Ginter, E.J., Glauser, A., \& Richmond, B.D. (1994). Loneliness, social support, and anxiety among two South Pacific cultures. Psychological Reports, 74, 875-879.

Gordon, S. (1976). Lonely in America. New York: Simon and Schuster.

Jylha M., \& Jokela, J. (1990). Individual experiences as cultural-a cross-cultural study on loneliness among the elderly. Aging and society, 10, 295-315.

Jones, W.H., Rose, J., \& Russell, D. (1990). Loneliness and social anxiety. In H. Leitenberg (Ed.) Handbook of social and evaluation anxiety. (Pp. 247-266). New York: Plenum. 
Kraut, R., Patterson, M., Lundmark, B., Kiesler, S., Mukopadhyay, T. \& Scherlis,W. (1998). Internet paradox: A social technology that reduces social involvement and psychological well-being? American Psychologist, 53 (9), 1017-1031.

Larson, R.W. (1990). The solitary side of life: An examination of the time people spend alone from childhood to old age. Developmental Review, 10, 155-183.

Lazarus, R.S. (2000). Toward better research on stress and coping. American Psychologist, 55 (6), 665673.

McCrae, R.R. \& John, O.P. (1992). An introduction to the five-factor model and its applications. Journal of Personality, 60, 175-215.

McWhriter, B.T. (1990). Loneliness: A review of current literature with implications for counseling and research. Journal of Counseling and Development, $68,417-423$.

Medora, N., Woodward, J., \& Larson J. (1987). Adolescent loneliness: A cross-cultural comparison of Americans and Asian Indians. International Journal of Comparative Sociology, 28, 204-210.

Mijuskovic, B. (1992). Organic communities, atomistic societies and loneliness. Journal of Sociology and Social Welfare, $19(2), 147-164$.

Moustakes, C.E. (1961). Loneliness. Englewood Cliffs, N.J.: Prentice-Hall.

Moustakes, C.E. (1972). Loneliness and love. Englewood Cliffs, N.J.: Prentice-Hall Inc.

Ornish, D. (1998). Love \& survival: The scientific basis for the healing power of intimacy. New York: HarperCollins.

Ostrov, E., \& Offer, D. (1980). Loneliness and the adolescent. In J. Hartog, J.R. Audy \& Y. Cohen (Eds.) The anatomy of loneliness. (Pp. 170-185). New York: International University Press.

Packard, V. (1972). Are there no roots in American? Sunday World Herald Magazine of the Midlands, 12 (Nov.), 5-7.

Peplau, L.A., Bikson, T.K., Rook, K.S. \& Goodchilds, J.D. (1982). Being old and living alone. In: L.A. Peplau \& D. Perlman (Eds.) Loneliness: A sourcebook of current theory, research and therapy. (Pp. 327-347). New York: Wiley-Interscience.

Rabasca, L. (1999, January). Happiness may increase with age. American Psychological Association Monitor, 30, 11 .

Rabasca, L. (2000). Growing old, staying spry. Monitor on Psychology, 3/(8), 70.

Revenson, T., \& Johnson, J. (1984). Social and demographic correlates of loneliness in later life. American Journal of Community Psychology, 21, 71-85.

Rokach, A. (1988). Theoretical approaches to loneliness: From a univariate to a multidimensional experience. Review of Existential Psychology and Psychiatry, 19, 225-254.

Rokach, A. (1990). Surviving and coping with loneliness. The Journal of Psychology, 124, 39-54.

Rokach, A. (1999). Cultural background and coping with loneliness. Journal of Psychology, 133 (2), $217-$ 229.

Rokach, A., \& Brock, H. (1998). Coping with loneliness. Journal of Psychology, 132 (1), 107-127.

Rokach, A., Ramberan, G., \& Bacanli, H. (2000). Coping with loneliness: A cross-cultural comparison. European Psychologist, 5 (4), 302-311.

Rook, K.S. (1984). Promoting social bonding. American Psychologist, 39, 1389-1407.

Rook, K.S. (1988). Toward a more differentiated view of loneliness. In S. Duck (Ed.), Handbook of personal relationships: Theory, research, and intervention (Pp. 571-589). New York: John Wiley \& Sons.

Rook, K.S. and Peplau, L.A. (1982). Perspectives on helping the lonely. In L.A. Peplau \& D. Perlman (Eds), Loneliness: A sourcebook of current theory, research and therapy (Pp. 351-378). New York: Wiley-Interscience.

Rosow, I. (1976). Status and role change through the life span. In R. Binstock \& E. Shannans (Eds.) Handbook of aging and the social sciences. New York: Van Nostrand Reinhold.

Roy, R. (1986). A psychosocial perspective on chronic pain and depression in the elderly. Social Work in Health Care, 12 (2), 27-36.

Sadler, W.A. (1987). Dimensions in the problem of loneliness: A phenomenological approach in social psychology. Joumal of Phenomenological Psychology, 9, 157-187.

Saxton, L. (1986). The individual, marriage, and family. Belmont, CA: Wadsworth Publishing.

Schneider, K.J. (1998). Toward a science of the heart: Romanticism and the revival of Psychology. American Psychologist, 53 (3), 277-289.

Segall, M.H., Lonner, W.J., \& Berry, J.W. (1998). Cross-cultural psychology as a scholarly discipline: On the flowering of culture in behavioural research. American Psychologist, 53 (10), 1101-1110.

Sermat, V. (1980). Some situational and personality correlates of loneliness. In J. Hartog, J.R. Audy, \& Y. A. Cohen (Eds.) The anatomy of loneliness (Pp. 305-318). New York: International University Press.

Solsten, E. (1994). Portugal: A country study. Federal Research Division, Library of Congress.

Sullivan, H.S. (1953). The interpersonal theory of psychiatry. New York: W.W. Norton.

Triandis, H.C. (1996). The psychological measurement of cultural syndromes. American Psychologist, 51, $407-415$. 
VanderVoort, D. (1999). Quality of social support in mental and physical health. Current Psychology, 18 (2), 205-222.

Vincenzi, H., \& Grabosky, F. (1987). Measuring the emotional/social aspects of loneliness and isolation. Journal of Social Behaviour and Personality, 2, 257-270.

Weil, A. (1997). Eight weeks to optimum health: A proven program for taking full advantage of your body's natural healing power. New York: Knopf.

Weiss, R.S. (1973). Loneliness: The experience of emotional and social isolation. Cambridge, MA: The MIT Press.

Walker, H.B. (1966). To compare loneliness. New York: Harper and Row.

Weintrob, H.L. (1987). Self disclosure as a marketable commodity. In M. Hojat \& R. Crandall (Eds.) Loneliness: Theory, research and application [special issue]. Journal of Social Behavior and Personality, 2 (2), 77-88.

Wilson, D., Sibanda, J., Sibanda, P., \& Wilson, C. (1989). Personality concomitants of loneliness among black and white male Zimbabwean adolescents. Journal of Social Psychology, I29 (4), 577-578. 


\section{APPENDIX A \\ Coping with Loneliness-Sample Items}

\section{Factor I: Reflection and Acceptance}

I turned loneliness into a time for reflection (.61)*

I came to accept how I felt (.59)

I tried to focus on what really mattered to me in life (.59)

I came to view being alone as an opportunity to think things through and set new goals for myself (.64)

\section{Factor 2: Self-Development and Understanding}

I actively sought to make new friends at social groups I attended (.40)

I went back to work after years of being at home (.41)

I sought professional help from a medical doctor (.57)

I enrolled in personal development seminars (.51)

\section{Factor 3: Social Support Network}

I went to more parties and social functions (.63)

I renewed old friendships (.49)

I spent time at places where I knew there would be a lot of people (.45)

I corresponded with friends/family more frequently (.42)

\section{Factor 4: Distancing and Denial}

I purposely built walls around myself (.55)

I avoided social functions (.40)

I drank alcohol to excess (.58)

I denied to myself that anything was wrong (.48)

\section{Factor 5: Religion and Faith}

I actively sought to make friends at my church (.56)

I sought answers to my problems in prayer (.75)

I felt strengthened and comforted by my faith in God (.76)

My attendance at religious services increased (.68)

\section{Factor 6: Increased Activity}

I took up a new hobby $(.51)$

I took up a new sport (.46)

I got a part-time job (.42)

I immersed myself in work (.53)

* The factor loading of the item 
Copyright of Current Psychology is the property of Transaction Publishers and its content may not be copied or emailed to multiple sites or posted to a listserv without the copyright holder's express written permission. However, users may print, download, or email articles for individual use. 